\title{
A motivação metafórica na gramaticalização Do marcador evidencial de acordo com
}

\author{
Metaphorical motivation in grammaticalization \\ Of evidential marker in accordance with
}

\section{Cláudia Ramos Carioca}

Universidade da Integração Internacional da lusofonia Afro-Brasileira - UNILAB - Redenção - Ceará - Brasil

\begin{abstract}
Resumo: Este artigo objetiva explicitar como a motivação metafórica influenciou a gramaticalização da expressão "de acordo com" como item evidencial. Metodologicamente, a análise fundamenta-se teoricamente nos estudos de Hopper e Traugott (2003), Heine et al (1991) e Sweetser (1991) para o aporte teórico acerca do processo de gramaticalização, enquanto Lakoff e Johnson (1980) estabelecem as balizas da Teoria da Metáfora Conceptual, dentre outros; e utiliza ocorrências do corpus constituído para a pesquisa de tese "A Manifestação da Evidencialidade nos trabalhos acadêmicos de grau do Português Brasileiro Contemporâneo" (CARIOCA, 2011), estabelecendo uma correlação sistemática entre o domínio fonte relacionado ao termo lexical "acordo" com a categoria evidencialidade (domínio alvo) do termo preposicional "de acordo com". Geralmente, esta marca evidencial é utilizada na linguagem acadêmica para explicitar um efeito de sentido que caracteriza um baixo comprometimento com o que está sendo dito/escrito, visto que a evidencialidade é uma categoria linguística que permite a manipulação estratégica das informações quanto à fonte do conhecimento. "De acordo com", então, expressa uma afirmação asseverada não a partir do autor do texto, mas de alguém especializado no assunto que está sendo abordado no momento. Conclui-se, então, que a convenção acadêmica também colaborou para a motivação metafórica do marcador evidencial "de acordo com".
\end{abstract}

Palavras-chave: Metáfora. Metodologia. Interpretativismo, Dialogismo. Pensar Alto em Grupo.

\begin{abstract}
This article aims to explain how the metaphorical motivation influenced the grammaticalization of the phrase "in accordance with" as an evidential item. Methodologically, among other authors, the theoretical grammaticalization process framework for the analysis is based on Hopper and Traugott (2003), Heine et al (1991) and Sweetser (1991) while Lakoff and Johnson (1980) establish the basis for Conceptual Metaphor Theory. The work uses instances of a corpus built for the thesis research entitled "The Manifestation of evidentiality in degree academic papers in Contemporary Brazilian Portuguese" (CARIOCA, 2011), establishing a systematic correlation between the source domain related to the lexical term "agreement" with the evidentiality category (target domain) of the prepositional term "in accordance with". Generally, this evidential marker is used in academic language to explain a sense effect which indicates low commitment to what is being said / written, since evidentiality is a linguistic category which allows the strategic manipulation of information as to the source of knowledge. "In accordance with" then expresses an asserted claim not from the author's text but that of someone skilled in the subject that is being addressed. It follows then, that the academic convention also contributed to the metaphorical motivation of the evidential marker "in accordance with".
\end{abstract}

Keywords: Metaphor. Metaphorical motivation. Grammaticalization. Evidentiality. 


\section{Introdução}

O jogo metafórico subjacente à linguagem extrapola qualquer tipo de limitação na relação objetividade/subjetividade que envolve cada âmbito discursivo. Logo, o discurso acadêmico não é desmetaforizado como regra por causa de seu alto grau de objetividade e suposta imparcialidade, além de que pode até colaborar com a evolução semântica de determinados vocábulos ou expressões.

Tendo isso em vista, este artigo tenta explicitar como a motivação metafórica influenciou a gramaticalização da expressão de acordo com como item evidencial. A evidencialidade é uma categoria linguística utilizada como estratégia que permite a manipulação das informações quanto à fonte do conhecimento e ao grau de (des)comprometimento do produtor com essa fonte e se manifesta por meio de marcadores evidenciais, os quais ou estão já gramaticalizados ou em processo de gramaticalização.

Esse processo se caracteriza pela mudança linguística que afeta o conteúdo semântico de uma palavra ou expressão, com perda de significado lexical e ganho de significado gramatical (mais abstrato). Essa mudança tem relação com a metáfora, por ser entendida como um processo de transferência semântica, em que estendemos, a novos contextos, o uso de uma forma pela relação de similaridade.

Metodologicamente, a análise fundamenta-se teoricamente nos estudos de Hopper e Traugott (2003), Heine et al (1991) e Sweetser (1991) para o aporte teórico acerca do processo de gramaticalização, enquanto Lakoff e Johnson (1980) estabelecem as balizas da Teoria da Metáfora Conceptual, dentre outros; e utiliza ocorrências do corpus constituído para a pesquisa de tese "A Manifestação da Evidencialidade nos trabalhos acadêmicos de grau do Português Brasileiro Contemporâneo" (CARIOCA, 2011), estabelecendo uma correlação sistemática entre o domínio fonte relacionado ao termo lexical "acordo" com a categoria evidencialidade (domínio alvo) do termo preposicional "de acordo com".

A escolha do corpus baseou-se no posicionamento de Coracini (1991, p. 133) de que mesmo a linguagem científica, que supomos ser literal, é rica em metáforas, quando afirma que:

O discurso científico, sobretudo o de tipo primário, visto ortodoxamente como imparcial e objetivo, não poderia ou não deveria apresentar metáforas de espécie alguma (essa seria, ao menos, a expectativa). Sabese, no entanto, que não é bem isso o que de fato ocorre: o tipo de metáforas de que a ciência se serve é considerado pelos linguistas como 'metáforas mortas' e, por isso mesmo, já com tendência à literalidade e à denotatividade, uma vez que teriam perdido todo valor de surpresa, imagem e expressividade, características da linguagem metafórica. Assim, passando a fazer parte do jargão do discurso científico, esses termos, vistos como técnicos, seriam 'monossêmicos ou mono-referenciais' em oposição aos termos metafóricos propriamente ditos (cf. Rafalovitch, 1983; p. 43). É contra esta visão simplista que me posicionarei neste capítulo, em que tentarei mostrar que a metáfora constitui um fenômeno que extrapola o âmbito do estritamente linguístico e que não pode ser analisado em oposições radicais e estanques.

Desse modo, far-se-á a seguir uma breve exposição, por tratar-se de um artigo, dos fundamentos teóricos desta pesquisa.

\section{Motivação metafórica}

O estudo da metáfora principia nos argumentos aristotélicos sendo definida como o uso do nome de uma coisa para designar outra, e manifestada não só na poesia e na retórica, mas já abarcando a linguagem cotidiana.

Ao longo de mais de dois séculos, tal estudo evoluiu e, hoje, é comum o entendimento da metáfora fundamentada em duas propostas principais: a metáfora lingüística (figura de linguagem) e a metáfora conceitual (figura de pensamento).

É a partir da publicação da pesquisa de Lakoff e Johnson (1980), no livro Metaphors We Live By, que os estudos metafóricos ganham essa nova visão, pois a metáfora passa a não ser considerada apenas como uma figura de linguagem, mas também como 
uma figura de pensamento, que expressa tanto a linguagem como as ações humanas, conforme explicitam os próprios autores ao dizer que:

Nós, descobrimos, [...], que a metáfora está infiltrada na vida cotidiana, não somente na linguagem, mas também no pensamento e ação. Nosso sistema conceptual ordinário, em termos do qual não só pensamos mas também agimos, é fundamentalmente metafórico por natureza (LAKOFF \& JOHNSON, 1980, p. 45).

A teoria desenvolvida pelos pesquisadores é conhecida como Teoria da Metáfora Conceptual e estabelece alguns elementos importantes para 0 estudo metafórico, os quais foram elencados resumidamente por Farias e Marcuschi (2006, p. 123):

(1) domínio-fonte (mais concreto); (2) domínio-alvo (mais abstrato); (3) experiência (de base corpórea); (4) estruturas neurais que correspondem ao domínio-fonte e ao domínioalvo; (5) a relação entre os diferentes domínios (sempre que um domínio-fonte é ativado, pode ocorrer ativação de outro(s) domínio(s)-alvo); (6) expressões lingüísticas metafóricas (a partir da coocorrência e recorrência entre domínios são geradas matrizes que se manifestam em expressões lingüísticas licenciadoras); (7) mapeamento ou correspondência entre domínios; (8) mapeamentos adicionais entre domínios que geram inferências; (9) realização não-verbal de metáforas e (10) modelos culturais que são manifestações específicas de representações a respeito do mundo.

Segundo Macedo (2006, p. 28) percebe-se "a presença do modelo conexionista especialmente na versão mais recente da teoria da metáfora conceitual" no estudo dos elementos citados para uma explicação da capacidade categorizacional. A autora destaca que, para Lakoff e Johnson (1999), “a categorização é conseqüência das nossas especificidades corpóreas, sendo que os tipos de categorizações que fazemos resultam do tipo de cérebros que possuímos e das interações e ações que desempenhamos no mundo".

Destarte, a organização das categorias a partir da noção de protótipos especifica mais claramente a visão de que "uma estrutura neural nos permite fazer algum tipo de tarefa inferencial ou imaginativa com respeito a uma categoria" (LAKOFF; JOHNSON, 1999, p. 19).

A motivação metafórica surge, então, da interrelação dos fatores citados até aqui, ou seja, a metáfora se constrói na diversidade do uso lingüístico relacionando a inferência com uma categoria.

De fato, mesmo entendendo a metáfora como figura de pensamento, é a partir de sua manifestação na linguagem em uso gerada em um contexto discursivo que ela é compreendida. Para Vereza (2007, pp. 490-491):

Podemos ver assim que, depois de ter transferido o lócus da metáfora da linguagem para o pensamento, considerando a primeira apenas como um espaço em que as evidências da metáfora conceptual seriam materializadas, a pesquisa na área da metáfora tem se voltado, mais recentemente, para a linguagem a partir de uma perspectiva discursiva, ou seja, para o uso da metáfora em situações reais de linguagem em uso. No entanto, é muito importante ressaltar que isso não implica um retrocesso, ou seja, um retorno à visão puramente lingüística da metáfora, típica da visão tradicional discutida anteriormente. A visão discursiva da metáfora pressupõe a metáfora conceptual como importante ferramenta na construção de significados em determinados campos do discurso.

Partindo desse princípio é que este artigo intenta explicitar a motivação metafórica na gramaticalização do marcador evidencial de acordo com em textos acadêmicos de grau. Dessa forma, manifesto na linguagem acadêmica em uso e gerado em um contexto discursivo de trabalhos de grau.

Como o objeto aqui estudado é um recurso gramatical, faz-se necessário ressaltar a pesquisa de Sardinha (2007, p. 45) sobre a metáfora gramatical, definida como "um termo usado na lingüística sistêmico-funcional em referência ao uso de um recurso gramatical para exprimir uma função que não Ihe é intrínseca".

Ocorre, então, o que o autor estabelece ser uma realização indireta como o uso metafórico de um item, significando que o nível do sentido (semânticodiscursivo) não é verificado diretamente no nível da expressão (léxico-gramatical). Outro fato importante destacado neste trabalho é o termo tensão estratal, 
tida como o fenômeno gerador da metáfora gramatical, e entendida como a falta de correspondência entre a função original de um recurso lingüístico e seu emprego. Teoricamente, significa que o estrato léxico-gramatical perde mapeamentos no estrato semântico-discursivo ou o contrário (SARDINHA, 2007, p. 56).

\section{Gramaticalização}

O processo de gramaticalização, sob uma perspectiva diacrônica, foi citado pela primeira vez por Meilet (1912), que estabeleceu três classes de palavras (as principais, as acessórias e as gramaticais) e propôs a existência de uma transição gradual entre elas.

Hopper e Traugott (1993, p. 1), por sua vez, tratam a gramaticalização como o processo em que "tanto itens lexicais e construções formam-se em certos contextos lingüísticos para exercer funções gramaticais quanto itens gramaticais desenvolvem novas funções gramaticais". Assim, uma forma que já está gramaticalizada pode ainda se tornar mais gramaticalizada.

Na relação metáfora e gramaticalização, Heine et al (1991) estabelece grande importância à metáfora dentro dos fatos da gramaticalização, sendo o processo metafórico visto como uma estratégia cognitiva observável, por exemplo, em escalas que indicam unidirecionalidade no processo de gramaticalização: espaço > tempo > texto. Sua interpretação propõe que os elementos que projetam o sentido da categoria cognitiva espaço, ao se gramaticalizarem, irão assumir outros sentidos localizados no texto, podendo passar pelo sentido da categoria cognitiva de tempo.

Hopper e Traugott (1993), assim como Heine et al (1991), consideram a metáfora como um dos principais fatores de motivação de processos de gramaticalização em geral.

Nesse processo, a motivação metafórica tem início na criatividade humana, a qual é entendida como inerente à habilidade cognitiva humana, formando novos significados abstratos enraizados em significados concretos. Na discussão dos significados, tanto Heine et al (1993) como Sweetser (1991) os especificam como domínios, que mostram que o significado lingüístico é processado cognitivamente.

Para Sweetser (1991), a linguística cognitiva é a base do tratamento dado às mudanças semânticas e defende que a teoria que analisa a descrição das mudanças semânticas gerais deve também descrever o caso específico de gramaticalização. Contrariando as posições de Hopper e Traugott (1993) e Heine et al (1991) no que diz respeito ao tratamento da gramaticalização, já que estes estabelecem que os processos específicos de gramaticalização podem suscitar a formulação de teorias linguísticas que ultrapassam o âmbito da gramaticalização.

\section{Marcadores evidenciais}

Com base em Dik (1989) e Hengeveld (1988, 1989), Neves (1996, p.173) explica que a função representacional é responsável pelo reconhecimento que o enunciatário faz da situação, e a função interpessoal pelo reconhecimento que ele faz da intenção comunicativa do enunciador. A essas funções correspondem os quatro níveis de instâncias de modalização dos enunciados e, a partir deles, projeta-se uma distinção para três tipos de modalidade: a) no nível do predicado, tem-se a modalidade inerente; b) no nível da predicação, configura-se a modalidade objetiva, que apresenta uma subdivisão em: modalidade epistêmica e modalidade deôntica; e c) no nível da proposição, ocorre a modalidade epistemológica, que se subdivide em: modalidade subjetiva e modalidade evidencial.

A evidencialidade chama a atenção pelo fato de ser considerada como meio de revelação da fonte de um conteúdo proposicional, marcando também o grau de comprometimento do falante com a verdade da proposição (BYBEE; FLEISCHMANN, 1995, p.4).

Para Hengeveld (1988) a evidencialidade se abriga na categoria modalidade (modalidade evidencial) e toma como escopo a proposição, subdividindo-se em inferencial, citativa e experiencial. 
A modalidade epistemológica evidencial oferece, ao falante, um modo de não se apresentar como a fonte da informação contida na proposição, ainda que faça um julgamento sobre essa informação, oportunizando a apresentação de uma produção que não é sua. Desse modo, na subclassificação proposta por Hengeveld (1988), tem-se que:

a) a evidencialidade inferencial caracteriza uma produção que foi inferida a partir de uma evidência, conforme se observa no exemplo ${ }^{1}$ seguinte:

(1) PARECE-NOS QUE devem ser aplicados à teoria fantástica os mesmos preceitos que lhe regem na ficção (p.108). (D1.C.21)

Nota-se que o produtor textual relata uma informação obtida por meio de raciocínio. Projetando, no informe, esse aspecto, utiliza uma marca evidencial que aumenta a relevância de seu raciocínio, pois, se ele apenas dissesse "devem ser aplicados à...", não estaria explicitando a sua participação na construção do que é dito e, ao mesmo tempo, atenuando a certeza da informação.

b) a evidencialidade citativa caracteriza uma produção projetada a partir de uma outra fonte que não é o falante, tal como no exemplo a seguir:

(2) A Revista Set, [...], APONTOU Wood Allen COMO o quinto melhor cineasta ao mesmo tempo em que foi apontado como o segundo pior (p.7). (D6.I.01)

Observa-se que o produtor textual indica claramente a fonte da informação que ele está veiculando. Esta citação promove uma atenuação da responsabilidade do produtor textual com o que está sendo dito, pois não é ele quem aponta "Wood Allen como o quinto melhor...", mas uma outra fonte, a revista que também servirá como suporte para outras

\footnotetext{
1 Optou-se por utilizar os exemplos do corpus da pesquisa anteriormente mencionada na introdução, ao invés dos exemplos do autor em discussão, devido à falta dos mesmos no texto pesquisado, encontrando-se apenas as expressões It seems e It appears, no que diz respeito aos evidenciais citativo e experiencial (HENGEVELD, 1988, p.239).
}

informações que venham a ser organizadas a partir desta.

c) a evidencialidade experiencial caracteriza uma informação derivada de experiência vivida por uma fonte, tal como o exemplo que segue:

(3) Devo registrar que VI referência a um filme de 1919 feito no Rio de Janeiro, o longa Alma Sertaneja, de Luiz de Barros (p.18). (D8.I.13)

Verifica-se que a informação dada foi vivenciada pelo produtor textual, já que o verbo "ver" se refere a uma experiência física sensorial. Logo, o produtor textual explicita um alto envolvimento com a informação relatada, sendo ele próprio a fonte da informação.

Segundo Carioca (2011), os marcadores evidenciais se manifestam no Português Brasileiro Contemporâneo por meio de variados itens lexicais classificados gramaticalmente em substantivos, verbos, adjetivos, preposições, conjunções, como também através das convenções da ABNT.

\section{0 item evidencial de acordo com}

Neste artigo far-se-á apenas uma discussão inicial acerca da explicitação do processo de gramaticalização do item lexical de acordo com, já que tal assunto necessita de um estudo bastante complexo envolvendo um aporte teórico com ampla autenticidade científica

O item lexical de acordo com é considerado gramaticalmente uma locução prepositiva ${ }^{2}$ - conjunto de duas ou mais palavras com valor de preposição (palavra invariável que liga dois termos) - pelos critérios estabelecidos na Norma Gramatical Brasileira (NGB). No que diz respeito à classificação das preposições em essenciais e acidentais, acreditase que de acordo com está incluso nestas, devido ao seu uso ser o mesmo dos itens lexicais conforme,

\footnotetext{
2 O item em estudo não foi encontrado no rol de locuções prepositivas na forma manifesta em nenhuma gramática escolar ou mesmo nas gramáticas utilizadas nos cursos de Letras das universidades brasileiras.
} 
consoante e segundo, considerados preposições acidentais por serem provenientes de outras classes gramaticais. Entretanto, também pode substituir a preposição essencial para, levantando, então, uma dúvida em relação à sua classificação. No exemplo (04) que segue, verifica-se a utilização do item de acordo com e, em seguida, fazemos uma simulação de troca do item em estudo com os supracitados, para averiguação de perda de sentido ou não:

(4) DE ACORDO COM Barros et al (1991, p. 7): “...as distorções atuais são expressões inequívocas de adoção de políticas setoriais... (p. 12). (M2.I.10)

(4a) CONFORME Barros et al (1991, p. 7): “...as distorções atuais são expressões inequívocas de adoção de políticas setoriais...

(4b) CONSOANTE Barros et al (1991, p. 7): “...as distorções atuais são expressões inequívocas de adoção de políticas setoriais...

(4c) SEGUNDO Barros et al (1991, p. 7): “...as distorções atuais são expressões inequívocas de adoção de políticas setoriais...

(4d) PARA Barros et al (1991, p. 7): “...as distorções atuais são expressões inequívocas de adoção de políticas setoriais...

Observa-se que não há nenhuma perda de significado na troca dos itens lexicais, ou seja, o sentido do que está sendo dito em (4a-d) permanece inalterado.

O verbo "acordar" /e'kordar/, evoluído do latim accordare, aparece nos dicionários como verbo transitivo (realizar acordo; resolver acordo; pôr em harmonia, conciliar) e como verbo reflexivo (estar de acordo; lembrar-se; resolver-se), derivando regressivamente a palavra acordo, que consta nos dicionários como substantivo masculino, significando: ajuste, convenção, conciliação, concordância, conformidade, entendimento das partes num contrato.

Ao sugerir que de acordo com é uma expressão metafórica manifesta lingüisticamente e gerada a partir da metáfora conceitual "o entendimento é um acordo", estabelece-se uma correlação sistemática na metáfora conceitual entre o domínio-fonte - aquele a partir do qual conceitualizamos alguma coisa metaforicamente, tomado como domínio concreto, que é realizável relacionado ao termo lexical "acordo" com o domínioalvo - aquele que desejamos conceitualizar, tomado como domínio abstrato - relacionado ao termo lexical "entendimento". Então, quando se diz de acordo com exprime-se um sentido de um entendimento entre as partes com a efetivação de um acordo.

Utilizada academicamente, esta metáfora produz tal efeito. Como no exemplo a seguir:

(5) DE ACORDO COM Emília Moreira: "A produção canavieira requeria tecnicamente a instalação de canaviais... (p. 27). (M3.F.48)

O produtor do texto acadêmico estabelece um entendimento com a idéia da autora citada, daí expressa o fato a partir do uso do item de acordo com, que já está gramaticalizado na língua, pois passou por uma mudança linguística que afetou seu conteúdo semântico, com perda de significado lexical e ganho de significado gramatical (mais abstrato):

acordo (substantivo) < de acordo com

(preposição) < de acordo com (conjunção)

As conjunções conformativas exprimem conformidade de um fato com outro, definição dos itens lexicais conforme, segundo e consoante, citados anteriormente. Em vista de que a locução prepositiva de acordo com é utilizada em mesma situação de uso das conjunções citadas, então se depreende que a mesma também pode ser usada como tal. Entretanto, de acordo com não é equivalente a todas as conjunções conformativas, consoante se observa a seguir:

(6) SEGUNDO Estela, o retorno era mínimo, o acesso pouco e era um serviço bastante oneroso para o colégio (p. 47). (M1.A.109) 
(6a) CONFORME Estela, o retorno era mínimo, o acesso pouco e era um serviço bastante oneroso para o colégio (p. 47).

(6b) CONSOANTE Estela, o retorno era mínimo, o acesso pouco e era um serviço bastante oneroso para o colégio (p. 47).

(6c) COMO Estela, o retorno era mínimo, o acesso pouco e era um serviço bastante oneroso para o colégio (p. 47).

(6d) QUE Estela, o retorno era mínimo, o acesso pouco e era um serviço bastante oneroso para o colégio (p. 47).

(6e) DE ACORDO COM Estela, o retorno era mínimo, o acesso pouco e era um serviço bastante oneroso para o colégio (p. 47).

No exemplo (6), a ocorrência de perda de sentido ocorreu apenas em (6c) e (6d) quando da troca das conjunções conformativas.

Como item evidencial, a expressão de acordo com manifesta uma relação de baixo comprometimento com o que está sendo dito, pois, apesar de significar um acordo entre as partes, evidencia um distanciamento quanto à fonte do conhecimento da informação entre as partes, é como se $o$ autor dissesse que concorda com ela, mas foi ela quem disse e não ele.

Quando no exemplo (7) adiante o produtor escolhe usar o termo de acordo com, ele expressa o pensamento do autor e não o dele, promovendo uma aparente neutralidade com 0 que está sendo dito/escrito e denotando um grau menor de adesão à tese defendida pelo estudioso:

(7) DE ACORDO COM Lima (1995) "[...] o período de 1935 a 1945 foi marcado pelo autoritarismo de Getúlio Vargas (p. 31). (M10.A.67)

As marcas evidenciais que caracterizam 0 baixo comprometimento são utilizadas de modo claro e específico em citações de idéias e pensamentos, as fontes são explicitadas de modo relativamente neutro, sendo algumas dessas marcas manifestas através das preposições e/ou conjunções, caso do item de acordo com.

A sua utilização não é usual no dia-a-dia, mas em uma linguagem mais especializada, como é o caso do discurso acadêmico aqui investigado.

No que diz respeito às ocorrências no corpus foram verificados 37 casos de uso da marca evidencial de acordo com de um total de 212 ocorrências de seus termos similares (conforme, segundo e para). O percentual atingido de $17,45 \%$ é considerado baixo, tendo em vista que 0 item segundo prevaleceu consideravelmente na análise.

\section{Considerações finais}

As considerações feitas nesta seção não são, necessariamente, finais, tendo em vista $O$ amplo espectro da pesquisa efetivada. A tentativa de se estabelecer resultados conclusos esbarra em algumas lacunas deixadas em aberto e que possibilitarão a retomada do estudo em questão. Com tal esclarecimento, passo a discorrer sobre alguns resultados iniciais.

A motivação metafórica estabelecida na gramaticalização da expressão de acordo com como item evidencial advém da especificidade do ato formal de um acordo como o entendimento entre as partes, só que especificando uma das partes - no caso o autor citado no texto -, estabelecendo um afastamento da responsabilidade em relação ao que foi dito por parte do produtor textual.

Geralmente, esta marca evidencial é utilizada na linguagem acadêmica para explicitar um efeito de sentido que caracteriza um baixo comprometimento com o que está sendo dito/escrito, visto que a evidencialidade é uma categoria lingüística que permite a manipulação estratégica das informações quanto à fonte do conhecimento. De acordo com, então, expressa uma afirmação asseverada não a partir do autor do texto, mas de alguém especializado no assunto que está sendo abordado no momento.

O processo de gramaticalização se caracteriza pela mudança lingüística que afeta o conteúdo semântico da expressão de acordo com, com perda 
de significado lexical - acordo como expressão nominal - e ganho de significado gramatical - de acordo com como expressão prepositiva e/ou expressão conjuntiva.

Essa mudança tem relação com a metáfora, por ser entendida como um processo de transferência semântica, em que estendemos, a novos contextos, o uso de uma forma pela relação de similaridade, aqui convencionalizada pelo discurso acadêmico mediante a relação de uso em citações diretas. No que concerne à convenção, Moura (2007, p. 423) ratifica que:

\begin{abstract}
A metáfora é um dos usos lingüísticos mais livres e criativos disponíveis para a mente humana, com enorme valor cognitivo. No entanto, essa criatividade não significa que não exista algum grau de convenção no uso metafórico, mesmo no caso de metáforas novas. De um modo geral, os teóricos concordam que a convenção condiciona de alguma forma a interpretação das metáforas.
\end{abstract}

Assim sendo, a convenção acadêmica também colaborou para a motivação metafórica do marcador evidencial de acordo com.

\section{Referências}

BYBEE, Joan; FLEISCHMAN, Suzanne (eds.). Modality in grammar and discourse. Amsterdam; Philadelphia: John Benjamins, 1995, 583 p.

CARIOCA, Cláudia Ramos. A Evidencialidade em textos acadêmicos de grau do Português Brasileiro Contemporâneo. Fortaleza: EDUFC, 2011, 228 p.

CORACINI, Maria José Rodrigues Faria. Um fazer persuasivo: o discurso subjetivo da ciência. São Paulo; Campinas: Educ; Pontes, 1991, $212 \mathrm{p}$.

DIK, Simon Cornelis. The theory of functional Grammar: pts. 1 \& 2. Dordrecht: Foris Publications, 1989, $986 \mathrm{p}$.
FARIAS, Emília Maria Peixoto; MARCUSCHI, Luiz Antônio. A Linguagem e o pensamento metafóricos. In: MACEDO, Ana Cristina Pelosi Silva de; BUSSONS, Aline Freitas (Orgs.). Faces da metáfora. Fortaleza: Expressão Gráfica e Editora, 2006, p. 111130.

HEINE, Bernd; CLAUDI, Ulrike; HÜNNEMEYER, Friederike. Grammaticalization: a conceptual framework. Chicago: University of Chicago Press, 1991, 328 p.

HENGEVELD, Kees. Illocution, mood and modality in a functional grammar of Spanish. Journal Semantics, v. 6. 1988, p. 227-269. Disponível em:

http://jos.oxfordjournals.org/content/6/1/227>. Acesso em: 13 mai. 2015.

Layers and operators in functional grammar. Journal Linguistics, n. 25, 1989, p. 127-157. Disponível em:

http://journals.cambridge.org/action/displayAb $\underline{\text { stract?fromPage }=\text { online } \& \text { aid }=2736760 \text { \&fileld }}$ $=$ S0022226700012123 > . Acesso em: 13 mai. 2015.

HOPPER, Paul J.; TRAUGOTT, Elizabeth Closs. Gramaticalization. Cambridge: Cambridge University Press, 1993, 300 p.

LAKOFF, George; JOHNSON, Mark. Metaphors we live by. Chicago; London: University of Chicago Press, 1980, 256 p.

Philosophy in the flesh: the embodiend mind and its challenge to western thought. New York: Basic Books, 1999, 640 p.

MACEDO, Ana Cristina Pelosi Silva de. Paradigmas cognitivos, linguística cognitiva e metáfora conceitual. In: MACEDO, Ana Cristina Pelosi Silva de; BUSSONS, Aline Freitas (Orgs.). 
Faces da metáfora. Fortaleza: Expressão

Gráfica e Editora, 2006, p. 23-36.

MEILLET, Antoine. (1912). Linguistique historique et linguistique générale. Paris: Champion, 1948, $234 \mathrm{p}$.

MOURA, Heronides. Relações paradigmáticas e sintagmáticas na interpretação de metáforas. In: Linguagem em (Dis)curso, v. 7, n. 3, setdez, 2007, p. 417-452. Disponível em: < http://linguagem.unisul.br/paginas/ensino/pos/ linguagem/linguagem-emdiscurso/0703/070305.pdf>. Acesso em 13 mai. 2015.

NEVES, Maria Helena de Moura. A modalidade. In: $\mathrm{KOCH}$, Ingedore Grunfield Villaça. (Org.). Gramática do português falado: desenvolvimentos. Campinas: EDUNICAMP/FAPESP, 1996, 526 p. (v. VI).

SARDINHA, Tony Berber. Metáfora. São Paulo: Parábola, 2007, 167 p. (Língua[gem], n. 24).

SWEETSER, E. From etymology to pragmatics. Cambridge: Cambridge University Press, 1991.

VEREZA, Solange Coelho. Metáfora e argumentação: uma abordagem cognitivo-discursiva. In: Linguagem em (Dis)curso, v. 7, n. 3, set-dez, 2007, p. 487-506. Disponível em: < http://www.portaldeperiodicos.unisul.br/index. php/Linguagem_Discurso/article/view/374/39 5>. Acesso em: 13 mai. 2015. 